\title{
Os tribunais e as novas tecnologias de comunicação e de informação
}

BOAVENTURA DE SOUSA SANTOS

1. Introdução

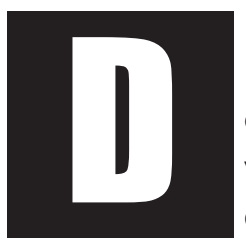

urante séculos os tribunais foram importantes fontes de informação e de comunicação social. Ainda o são hoje em sociedades camponesas, de vários continentes onde vive cerca de metade da população mundial. Nessas sociedades, a resolução de litígios é uma ocasião privilegiada para divulgar informação socialmente relevante tanto do ponto de vista fáctico como do ponto de vista normativo. Essa informação/comunicação é de dois tipos: explícita - o que se diz e se comunica - e implícita - o que se não diz nem se comunica porque se pressupõe conhecido. A criação de sentido e a possibilidade de inteligibilidade assenta nas duas. Sem a informação implícita não se entende a explícita.

O papel dos tribunais enquanto instâncias de informação e de comunicação social foi drasticamente alterado a partir do séc. XIX com a consolidação do estado moderno, o movimento da codificação, o monopólio estatal da justiça e a profissionalização da função judicial. A partir daí, o conhecimento técnico passou a dominar a informação e a comunicação, ao ponto de estas se transformarem, elas próprias, em artefactos discursivos técnicos de que são excluídos todos os que não dominam o conhecimento especializado que lhes subjaz. O conhecimento técnico-

* Director do Observatório Permanente da Justiça Portuguesa, Centro de Estudos Sociais. 
jurídico permitiu adensar e potenciar os fluxos de informação e de comunicação mas reduziu os agentes desse fluxo ao pequeno círculo dos profissionais intervenientes. O público não profissional, incluindo as partes e as testemunhas, passou de sujeito de informação a objecto de informação. $\mathrm{O}$ público deixou mesmo de poder intervir no processo e as partes e testemunhas passaram a intervir segundo códigos de informação e de comunicação que não conhecem ou não entendem.

Paralelamente, a dicotomia informação explícita/informação implícita foi substituída pela dicotomia informação relevante/informação irrelevante. A diferença crucial entre as duas dicotomias é que, enquanto na primeira os dois pólos fazem parte da mesma construção discursiva e são-lhe igualmente constitutivos e pertinentes, na segunda opera-se uma ruptura drástica entre o que é relevante e o que é irrelevante e de tal modo que o que é irrelevante, longe de ser informação, é transformado em ruído, um obstáculo à informação e à comunicação, que, como tal, deve ser erradicado. Por outras palavras, o irrelevante não é, como o implícito, uma informação diferente. É desinformação.

A profissionalização da informação e seus fluxos, combinada com a separação total entre informação relevante e informação irrelevante, foram os dois pilares em que assentou a legitimidade política dos tribunais modernos. Tratou-se de uma legitimidade política que operou por via da despolitização da função judicial, ou seja, pela redução da questão política do lugar da adjudicação judicial na nova conflitualidade social, à questão técnica do rigor profissional da adjudicação judicial, operando em circuito fechado, isolada da conflitualidade social.

À luz disto, não admira que os estudos, que começaram a surgir a partir de meados do séc. XX, sobre os tribunais enquanto sistemas de informação e de comunicação se refiram exclusivamente ao circuito interno, à informação e comunicação que circula no interior dos tribunais entre os diferentes sectores da instituição e entre os diferentes profissionais 
que nela actuam. Trata-se, pois, de uma informação técnica sujeita a critérios estritos de relevância partilhados por todos os operadores do direito. A elevada codificação linguística e semântica da informação em circulação fez com que ela se tornasse incomunicável para além do circuito institucionalprofissional. Foi assim que os tribunais e a actividade judicial se transformaram na mais esotérica das instituições e actividades estatais da modernidade.

É neste contexto que surge, a partir da década de noventa do século passado, a problemática da relação entre os tribunais e as novas tecnologias de comunicação e de informação (NTCI) e, em especial, da relação entre os tribunais e a comunicação social. Esta problemática é uma subespécie de uma outra muito mais ampla. Podemos distinguir nesta última dois vectores: o direito como variável independente e o direito como variável dependente. $\mathrm{O}$ primeiro vector diz respeito à vontade e à capacidade do Estado e do direito para regular as novas tecnologias e os novos interesses de comunicação e de informação e para incriminar e punir as novas actividades socialmente danosas que por via delas se tornaram possíveis, nomeadamente o cibercrime, a violação da privacidade, etc. O segundo vector diz respeito ao impacto da expansão exponencial das novas tecnologias e dos novos interesses informacionais e comunicacionais no direito e nas suas instituições, nomeadamente os tribunais.

Estes dois vectores são distintos, mas estão relacionados. São, por vezes, duas perspectivas sobre os mesmos fenómenos. Assim, a questão da capacidade e vontade regulatória do direito surge, muitas vezes, da necessidade de minimizar o impacto das novas tecnologias de comunicação e de informação no direito e suas instituições. Inversamente, a questão do impacto das novas tecnologias é o outro lado da constatação da incapacidade ou da ineficácia regulatória do direito.

\section{Os tribunais e o stress comunicacional}

Tendo esta articulação sempre em mente, ocupo-me aqui do segun- 
do vector, isto é, privilegio a questão do impacto. A partir da questão do impacto pretendo chegar à questão da regulação. No que respeita aos tribunais, o vector do impacto tem duas vertentes. A primeira vertente diz respeito à operacionalidade organizacional interna dos tribunais e ao impacto que nela podem ter as novas tecnologias de comunicação e de informação. Esta primeira vertente inclui questões como a informatização dos tribunais, as novas técnicas de gestão e seu impacto nas relações inter-profissionais no interior dos tribunais, o impacto da mediatização da justiça na funcionalidade interna dos tribunais e nas regras e estilos de actuação profissional, em especial, dos magistrados judiciais e magistrados do ministério público.

A segunda vertente diz respeito ao impacto das novas tecnologias de comunicação e de informação e, sobretudo, dos meios de comunicação na relação entre os tribunais e a sociedade entretanto informatizada e mediatizada. Esta segunda vertente é a mais polémica porque as suas dimensões técnicas são sobredeterminadas pelas suas dimensões políticas. Isto é, ao questionarem à abdicação moderna dos tribunais em serem fontes de informação e de comunicação socialmente relevantes, as novas tecnologias e os novos interesses da comunicação social suscitam a questão da legitimação social e política dos tribunais.

Como vimos, a abdicação comunicativa e informacional dos tribunais assentou em dois pilares: exclusividade conferida ao conhecimento técnico e profissional, por um lado, e, por outro, a distinção entre informação relevante e informação irrelevante. Ora, qualquer destes pilares é questionado pelas novas tecnologias e pelos novos interesses comunicacionais. Como os dois pilares foram cruciais para a despolitização dos tribunais, ao reduzirem a legitimidade política ao rigor e à eficácia técnica, não surpreende que o questionamento deles implique a repolitização dos tribunais, suscitando, assim, uma questão de legitimidade. Ao reporem a questão do papel dos tribunais na sociedade, as tecnologias e interesses comunicacionais repõem a questão do lugar da adjudicação judicial na conflitualidade social. Fazem-no por duas vias. Em 
primeiro lugar, questionam as prerrogativas que o conhecimento técnicoprofissional atribuiu a si próprio. Para as novas tecnologias e interesses comunicacionais, esse conhecimento não é um fim em si mesmo e, como tal, deve ser posto em equação com as questões substantivas, factuais e normativas, com os interesses e as motivações das partes em conflito e dos próprios operadores. São estas últimas as questões a que se pretende ter acesso, questões que o conhecimento técnico-profissional oculta ou revela de modo socialmente incompreensível, acesso que o conhecimento profissional bloqueia através da barreira técnica. Quando o conhecimento técnico-profissional é convertido de fim em meio ou instrumento, o óbvio passo seguinte é perguntar-se pelos fins para que é utilizado.

A segunda via de questionamento do conhecimento técnico-profissional diz respeito especificamente à distinção entre informação relevante e informação irrelevante. As novas tecnologias e interesses informacionais e comunicacionais têm critérios de relevância que não coincidem com os dos tribunais e, como tal, tentam impor os seus, sujeitando os operadores a um stress específico que designo por stress comunicacional: o serem postos na contingência de se terem de adaptar a critérios de relevância que lhe são estranhos e de terem de o fazer em linguagem profissionalmente incorrecta. O dilema neste stress comunicacional é que, mesmo quando os operadores do direito contestam os critérios dos media, acabam por se render a eles, quanto mais não seja porque a linguagem da contestação tem de ser a linguagem comum com que os meios de comunicação social os confrontam.

Por estas duas vias, as novas tecnologias e interesses informacionais e comunicacionais colocam a adjudicação judicial no contexto mais amplo da conflitualidade social onde estão em jogo questões tão amplas quanto a luta contra a corrupção, as desigualdades sociais, as discriminações sociais, a injustiça, etc., etc.. Ao ser colocada num contexto tão amplo, a adjudicação judicial é miniaturizada. Do efeito de miniaturização decorre que a análise dos limites da adjudicação judicial se torna mais convincente que 
a análise das possibilidades da adjudicação judicial. Nisto reside o questionamento da legitimidade social e política dos tribunais.

Passo a analisar com um pouco mais detalhe o segundo vector, o vector do impacto das novas tecnologias e interesses informacionais no sistema judicial em suas duas vertentes. As duas vertentes são, como referi, o impacto das novas tecnologias de comunicação e de informação na gestão dos tribunais e no acesso à informação, por um lado, e o impacto da comunicação social no relacionamento dos tribunais com a sociedade, por outro. Estas duas vertentes estão mutuamente implicadas, mas, curiosamente, são normalmente tratadas em separado por especialistas diferentes. Se a primeira vertente é, na aparência, mais técnica do que política, a segunda é, na aparência, mais política do que técnica. A verdade é que são ambas questões técnicas e políticas. O que acontece é que, vistas da perspectiva dos tribunais, as novas tecnologias de comunicação e de informação surgem na primeira vertente como solução e na segunda, como problema. No entanto, não se pode ter a solução sem o problema, tal como não se pode abordar a questão técnica sem a questão política. Exige-se, pois, uma análise integrada das duas vertentes.

\section{A sociedade de informação e a democracia}

A questão das relações entre as novas tecnologias de comunicação e de informação e o sistema judicial é uma subquestão de um debate muito mais amplo sobre o significado económico, social, político e cultural da revolução em curso nas tecnologias de informação e de comunicação. Falar de revolução implica já assumir a grande magnitude das transformações que ocorrem sob os nossos olhos. Essa magnitude aparece formulada de modo diferente nos diferentes campos sociais. Na economia fala-se do novo estádio do capitalismo, o capitalismo informacional e da nova economia electrónica; no domínio social, da sociedade de informação ou da 
sociedade em rede e, também, da info-inclusão e de info-exclusão; no domínio político, da política espectáculo e da democracia electrónica; no domínio cultural, fala-se da cultura global e de cibercultura. Em minha opinião, a transformação mais profunda está a ocorrer nas concepções de espaço e de tempo. Todas as instituições da modernidade foram constituídas na base de um espaço-tempo privilegiado, o espaço-tempo nacional, constituído por três temporalidades distintas: a temporalidade da deliberação política (que determinou, por exemplo, que haver eleições de quatro em quatro anos é adequado, mas não o seria se as houvesse em cada quatro meses), a temporalidade da acção burocrática do Estado (que determinou, por exemplo, o ciclo de tributação, a validade das cartas de condução, das licenças e dos bilhetes de identidade, etc.) e a temporalidade judicial que fixou o patamar da duração dos processos para além dos quais é possível falar de morosidade.

Este espaço-tempo está hoje a ser desestruturado sob a pressão de um espaço-tempo emergente, global e instantâneo, o espaço-tempo electrónico, o ciber-espaço. Este espaço-tempo cria ritmos e temporalidades incompatíveis com a temporalidade estatal nacional. O caso mais dramático é talvez o espaço-tempo global e instantâneo dos mercados financeiros, o qual inviabiliza ou torna muito difícil qualquer deliberação ou regulação por parte do Estado.

Não é fácil avaliar a extensão e a profundidade das rupturas em curso. $\mathrm{O}$ instituinte, por mais poderoso, tem de contar sempre com a inércia e a resistência do instituído. E este tem modos de se perpetuar no interior daquilo que o transforma. A questão do potencial transformador da revolução nas tecnologias de informação e de comunicação é, assim, uma das questões centrais suscitadas a propósito do espaço-tempo emergente. A outra questão é a do sentido político e cultural desse potencial transformador. Assim, mais uma vez se mostra que as questões técnicas e as questões políticas seguem na sombra umas das outras. A questão do sentido políti- 
co é bem formulada por Stefano Rodatà: "Estamos a caminhar para a vivência de uma democracia como se sonhava na velha Atenas ou para o mundo prefigurado em Orwell? (2000, p. 121)". A resposta é tão fácil de dar como difícil de executar: depende de nós. A dificuldade reside em que quanto mais tudo parece depender de nós, mais nós parecemos depender de tudo e, nomeadamente, das tecnologias da informação e da comunicação que, mais e mais, conformam o nosso quotidiano.

Em minha opinião, as novas tecnologias de comunicação e de informação são uma enorme oportunidade e um enorme risco. Uma não é possível sem o outro, mas é possível maximizar as oportunidades e minimizar os riscos. Para isso, é necessário criar e aplicar generalizadamente níveis de competência técnica e política nos cidadãos muito acima daqueles que a democracia liberal até agora foi capaz de gerar. Sobretudo depois da obra de Joseph Schumpeter, Capitalismo, Socialismo e Democracia, publicada em 1943, a teoria política liberal reduziu a participação democrática dos cidadãos à eleição dos decisores políticos. Partindo do pressuposto que os cidadãos não são competentes para participar nas decisões da governação, nem estão interessados em tal participação, o papel da cidadania democrática ficou circunscrito à escolha dos decisores. Foi assim que a democracia representativa se impôs em detrimento da democracia participativa.

As novas tecnologias de comunicação e de informação desestabilizam este status quo teórico e político a dois níveis. Por um lado, tornam muito mais caótica a relação entre decisores e decisões, de tal modo que o carácter democrático dos primeiros deixou de garantir o carácter democrático das segundas. Por outro lado, criam oportunidades insuspeitadas para desenvolver competência cidadã, competência para deliberar e tomar decisões políticas e não apenas para escolher os decisores políticos. O problema político central passa a ser o de como juntar a essa competência o interesse em a exercitar. Do modo como esse problema for resolvido dependerá o sentido político das transformações em curso. Ou serão maximizadas as 
oportunidades para fortalecer a democracia e a cidadania; ou serão maximizados os riscos de reduzir a vivência da democracia e da cidadania a níveis muito inferiores aos já baixos níveis que hoje prevalecem.

Com este pano de fundo, passo a analisar, brevemente, os dois vectores da relação entre as novas tecnologias de comunicação e de informação e os tribunais.

\section{O impacto das novas tecnologias de comunicação e de informação na gestão dos tribunais e no acesso dos cidadãos à justiça}

As $\mathrm{NTCl}$ apresentam um enorme potencial de transformação do sistema judicial, tanto na administração e gestão da justiça, na transformação do exercício das profissões jurídicas, como na democratização do acesso ao direito e à justiça. No que respeita à administração e gestão da justiça, as novas tecnologias podem ter um efeito positivo na celeridade e eficácia dos processos judiciais. Podem, por exemplo, substituir tarefas rotineiras, permitir um controlo mais eficaz da tramitação dos processos, melhorar a gestão dos recursos humanos, das secretarias judiciais e das agendas judiciais, permitir o envio de peças processuais em suporte digital, facilitar o acesso às fontes de direito e, por essa via, ajudar os operadores judiciais a conhecer e a interpretar o sistema jurídico, para muitos operadores judiciais, cada vez mais complexo.

No que respeita à democratização do acesso ao direito e à justiça, as novas tecnologias de informação possibilitam mais circulação de mais informação e, portanto, um direito e uma justiça mais próximos e mais transparentes. Por exemplo, facilitam o acesso a bases de dados jurídicos, a informações fundamentais para o exercício de direitos, e possibilitam o exercício fácil de um conjunto de direitos e de deveres dos cidadãos. É, hoje, possível, através de redes electrónicas, apresentar requerimentos, 
receber informações, pagar determinadas taxas ou impostos, ou mesmo consultar processos.

Muito brevemente, passo a referir algumas áreas e alguns exemplos concretos de aplicação das NTCI no domínio do sistema judicial.

\subsection{Recursos humanos}

O uso das novas tecnologias pode possibilitar uma maior produtividade, eficiência e redução de custos no domínio da gestão dos recursos humanos. Por exemplo, a Comissão Avaliadora das Reformas na Noruega concluiu que a informatização dos tribunais aumentou significativamente a eficácia de todo o sistema de justiça e permitiu a redução, em cerca de 10\%, dos funcionários administrativos (Santos e Gomes, 2001, p. 188). Todavia, a introdução no sistema judicial de formas de gestão moderna e da tecnologia que lhe está associada requer especial cuidado e sensibilidade. As mudanças nunca serão eficazes se ocorrerem de forma brusca e sem o envolvimento próximo dos magistrados e funcionários. Por exemplo, uma atitude de resistência pode transformar algo potencialmente benéfico em um problema. É fundamental, por isso, que os operadores judiciais sejam persuadidos da importância e das vantagens para o sistema judicial dos novos métodos de gestão e das NTCl. Para tal, o processo de mudança deve ser precedido, ou ocorrer em simultâneo, com as seguintes etapas:

a) Informação aos agentes judiciais sobre o funcionamento do sistema e de como são utilizados os recursos tecnológicos no seu interior;

b) Avaliação prévia dos preconceitos e das barreiras culturais existentes em relação à introdução de novas tecnologias;

c) Desenvolvimento de programas de formação permanente para os funcionários e magistrados sobre os novos métodos de gestão e sobre as NTCl que lhe estão associadas. É fundamental criar competência nos agentes judiciais para a utilização eficaz das NTCI. Para tal, é necessário criar e incentivar a frequência de programas de formação permanente de forma a diminuir o grupo dos infoexcluídos. Em matéria de formação 
é, ainda, fundamental prestar mais atenção à formação inicial, quer nas Faculdades de Direito - neste domínio é ainda muito grande a disjunção entre a importância social das $\mathrm{NTCl}$ e a sua desvalorização no ensino e na aprendizagem do direito -, quer nos programas de formação inicial de magistrados e advogados;

d) Finalmente é importante incentivar o desenvolvimento de relações de trabalho de maior proximidade entre os diferentes operadores judiciais.

\subsection{Comunicação interna}

As NTIC têm um efeito altamente positivo no que diz respeito à gestão da informação e da comunicação no interior do sistema judicial. No entanto, o recurso às NTCI pode trazer também dificuldades. A experiência comparada mostra que para a implementação eficaz de um sistema de informação é necessário assegurar um conjunto de condições prévias. Destaco as seguintes: a informatização deve ser precedida de uma auditoria aos procedimentos e usos existentes; o sistema de informação adoptado deve ser adaptável, rapidamente e a baixos custos, a novas circunstâncias e a novos objectivos organizacionais; deve proporcionar um acesso seguro e eficiente a todos os utilizadores; deve ser compatível com outros sistemas; e deve ser adequado às necessidades e objectivos da organização. A compatibilidade é crucial para sua eficácia. As pessoas só o utilizam, adequada e satisfatoriamente, se o considerarem eficiente e um auxiliar indispensável na realização do seu trabalho.

Acresce que o desenvolvimento de sistemas de comunicação e a implementação de inovações tecnológicas só serão verdadeiramente eficientes se se conseguir uma coordenação ao nível macro. Não basta que a informação circule, rápida e eficazmente, no interior de cada organização, sendo igualmente necessário que estes fluxos circulem no interior de toda a esfera pública.

No domínio da experiência comparada, destaca-se a experiência da 
Inglaterra e País de Gales, em especial com a criação e posterior modernização do Court Service Intranet, e a experiência do País Basco. Neste último caso, o plano de informatização desenvolvido tem como características estruturais a uniformização e a transparência dos procedimentos processuais; a universalidade, através da aplicação do plano aos órgãos de todas as jurisdições e instâncias da administração da justiça e serviços comuns (o objectivo final é desenvolver uma rede judicial de comunicações alargada aos órgãos da administração pública e a outras entidades, como as ordens profissionais e as universidades); e a especialização funcional das aplicações através da mecanização de todas as funções que integram as tarefas de ordem administrativa ou processual da competência das secretarias judiciais.

\subsection{Gestão de processos}

Os sistemas informatizados de gestão de processos são uma ferramenta essencial para a organização e tratamento, de forma rápida e eficiente, de grandes quantidades de informação e de documentos, tornando mais rápido e eficiente o trabalho dos tribunais. Por exemplo, eliminam a necessidade de realização de certas tarefas repetitivas; possibilitam a publicidade de informação relevante, sem que tal implique a realização manual dessa tarefa pelo funcionário judicial ou deslocações inconvenientes e morosas ao tribunal; permitem a recepção de documentos; ou a consulta de processos por via electrónica.

$\mathrm{Na}$ experiência comparada, o sistema de gestão de processos que nos parece mais eficiente é o utilizado nalguns tribunais dos EUA. O software é utilizado para recolher, organizar, processar, guardar e distribuir informação essencial do processo, possibilitando o uso de técnicas sofisticadas de gestão. A informação introduzida no sistema pode ser organizada, agregada e analisada de forma a que se identifiquem todos os movimentos dos 
processos entrados, pendentes e arquivados. A informação sobre um determinado processo pode estar disponível, em simultâneo, para vários utilizadores. Programas especiais podem retirar informação do processo informático para gerar automaticamente documentos pré-formatados (notificações, citações, etc.). Através de relatórios, processados pelo computador, é possível identificar os processos que estejam a exceder os parâmetros normais de tempo de duração, antecipando a resolução de possíveis problemas.

\subsection{Comunicação com o público}

Numa sociedade aberta e democrática os tribunais têm que se tornar mais acessíveis e mais próximos dos cidadãos. Os projectos de modernização dos tribunais e de introdução de novas tecnologias devem ser estrategicamente orientados para esse objectivo. As NTCI podem desempenhar um papel importante na interface dos tribunais com o público, como, por exemplo, através da introdução no sistema judicial de quiosques informativos ou de guias electrónicos.

O Court Service (agência estadual que tem a seu cargo a administração da maioria dos tribunais da Inglaterra e do País de Gales) desenvolveu o projecto Court Service Information Kiosk, cujo objectivo é disponibilizar informação através de quiosques automáticos. Como meio privilegiado de informação ao público foram, ainda, criadas linhas telefónicas de apoio ao cidadão e desenvolvido um site do Court Service na Internet. Os planos de reforma prevêem, ainda, a introdução, a curto prazo, de serviços on-line para responder rapidamente às questões e reclamações dos utentes.

Em alguns tribunais dos EUA foi instalado um sistema electrónico de informação ao público, idêntico ao existente nos aeroportos, com informações sobre a agenda de cada juiz, as salas onde se realizam os julgamentos e os respectivos horários.

Os terminais informatizados de atendimento são, também, um mé- 
todo alternativo ao fornecimento de serviços, sem a necessidade de utilização de recursos humanos. Podem disponibilizar informações detalhadas, em linguagem acessível, sobre temas que, normalmente, constituem fonte de preocupação para a maioria dos utentes dos tribunais, possibilitando o esclarecimento de dúvidas e rapidez no atendimento. Podem permitir, também, a consulta de marcações de julgamentos e dos horários dos tribunais e de departamentos públicos.

Na Holanda, o programa "Administração da Justiça no Século XXI", que tem como principal objectivo a modernização do sistema judicial, prevê, entre outras medidas, a intensificação do recurso à Internet, através da implementação do projecto "Electronic Desk Judicial Organization", que tem como objectivo central o de transpor as barreiras geográficas que dificultam o acesso à justiça.

No País Basco, foi criado o Sistema de Informação Documental (SID) com o objectivo de criar uma base de dados de doutrina e jurisprudência, que permite o acesso a qualquer pessoa. Ainda nesta Comunidade Autónoma, o designado Terceiro Plano de Informatização dos Tribunais prevê a criação de um Centro de Atendimento aos Utentes, preparado para dar informações sobre metodologia, organização e utilização das novas ferramentas informáticas.

A aproximação da justiça aos cidadãos constitui uma preocupação do Conselho da Europa, evidenciada em várias resoluções e recomendações, adoptadas pelo Comité de Ministros. Destaco sobre esta matéria duas recomendações recentemente publicadas: a Recomendação (2001) 3, do Comité de Ministros dos Estados-membros sobre o uso das novas tecnologias nos serviços prestados aos cidadãos, quer pelos tribunais, quer por outras instituições jurídicas e a Recomendação (2001) 2 sobre a concepção dos sistemas judiciários e dos sistemas de informação jurídica numa perspectiva de custo-benefício.

A primeira Recomendação parte da ideia que as novas tecnologias de informação se tornaram num instrumento indispensável para uma efi- 
caz administração da justiça nos estados europeus e aponta um conjunto de objectivos que devem presidir à informatização dos serviços de administração da justiça, designadamente o acesso à informação jurídica, o desenvolvimento da interacção dos serviços judiciários com o público, possibilitando a obtenção de informações sobre o andamento do processos e a obtenção de decisões por via electrónica.

A Recomendação (2001)2 do Comité de Ministros dos Estados-membros veio reafirmar a importância das modernas tecnologias de comunicação no sistema judiciário, melhorando a qualidade, celeridade, eficácia e eficiência do direito e da justiça nos Estados-membros e aproximando-os dos cidadãos. A Recomendação enfatiza que o uso das tecnologias de informação e de comunicação no funcionamento dos tribunais deve trazer vantagens em termos de custo/benefício e de produtividade; deve melhorar a qualidade da justiça; aumentar a transparência dos procedimentos; proporcionar sistemas mais simples e acessíveis; privilegiar a aprendizagem e a transferência de conhecimentos; e reforçar a segurança dos dados e proteger o seu carácter privado e confidencial.

Em Portugal, no que diz respeito à aplicação das NTCl à administração da justiça, tem-se vindo a dar alguns passos, não estando ainda feita a sua avaliação. Saliento quatro medidas. A primeira é a criação do Instituto das Tecnologias de Informação na Justiça, dotado de autonomia administrativa, financeira e patrimonial, sob a tutela do Ministro da Justiça. Este Instituto, cuja criação revela uma especial atenção da política governamental a esta matéria, tem competência para a concepção, emissão e avaliação de normas técnicas e para a gestão integrada da rede de informação e comunicações da justiça, fomentando a unificação de métodos e processos. A segunda medida é a aprovação, pela Resolução do Conselho de Ministros n. 138/98, do Plano de Informatização Judiciária. Este Programa identifica como objectivos prioritários, dotar os tribunais de infraestruturas informáticas e de comunicação que possibilitem a produção e circulação interna de informação por via electrónica e garantam a sua 
ligação com o exterior em condições de segurança e qualidade de acesso; produzir e implementar soluções informáticas que permitam o registo inicial e o acompanhamento de todo o ciclo processual, sem redundâncias de informação, e automatizem as tarefas repetitivas; definir e criar, ou consolidar, as estruturas de administração e de suporte dos sistemas informáticos dos tribunais; e melhorar o sistema de produção e acesso às bases de dados jurídicas.

A terceira medida que destaco é a possibilidade de acesso a bases de jurisprudência via Internet. A quarta refere-se à introdução, no âmbito do processo civil, de algumas medidas com recurso às $\mathrm{NTCl}$, como o pagamento das taxas de justiça através das ATM, a possibilidade de envio de peças processuais através de meios electrónicos e a videoconferência.

\section{Os riscos e as oportunidades nas relações difíceis entre o Direito, a Justiça e os meios de Comunicação Social}

A visibilidade do direito e dos tribunais é uma das consequências do desenvolvimento da sociedade da informação. Como escrevi anteriormente, os tribunais são "uma das instituições mais intrigantes do Estado Moderno"; sendo, há muito, órgãos de soberania, só muito recentemente ganharam visibilidade social junto da opinião pública (Santos et al., 1996, p. 19). Ainda que a notoriedade pública ocorra em casos que constituem uma fracção infinitesimal do trabalho judiciário é suficientemente recorrente para não parecer excepcional e para, pelo contrário, parecer corresponder a um novo padrão de intervencionismo judiciário. Acresce que este intervencionismo e a sua visibilidade mediática ocorre mais no domínio criminal do que nos domínios civil, laboral ou administrativo e assume, como seu feito mais distintivo, a criminalização de responsabilidade política. Dirige-se, muitas vezes, aos abusos de poder e aos agentes políticos que os protagonizam. 
Este novo protagonismo judiciário traduz-se num confronto com a classe política e com outros órgãos de soberania, nomeadamente o poder executivo. Estamos perante uma judicialização dos conflitos políticos que não pode deixar de traduzir-se na politização dos conflitos judiciários. Para além da judicilização dos conflitos políticos, a notoriedade dos tribunais está relacionada com a explosão de litigiosidade, induzida pelas dividas de consumo e pela pequena criminalidade contra a propriedade, directa ou indirectamente relacionada com o tráfico e o consumo de drogas. Esta vaga expansionista de pequena criminalidade e os sintomas de insegurança social que gerou trouxeram para a ribalta mediática os tribunais. Um outra face da visibilidade dos tribunais reside no despontar de novos tipos de criminalidade, com forte repercussão pública, como o crime económico organizado, as associações criminosas, a corrupção, o tráfego de droga e de armas, de crianças, de prostitutas e de órgãos para transplantes.

É óbvio que nenhuma destas transformações sociais teriam retirado os tribunais da obscuridade e do silêncio a que desde sempre estiveram remetidos se, entretanto, não tivessem ocorrido mudanças profundas, tanto técnicas, como políticas, no domínio das tecnologias de informação e de comunicação. É que, de par com a revolução tecnológica no sector, ocorreu uma outra revolução, a revolução da desregulamentação, da liberalização, da privatização do sector de informação e de comunicação que deu azo à emergência da pujante e multifacetada indústria da informação e da comunicação. Foi no bojo da expansão desta indústria que os tribunais se transformaram, quase de repente, num conteúdo apetecível. A plácida obscuridade dos processos judiciais deu lugar à trepidante ribalta dos dramas judiciais.

As disjunções entre a lógica da acção mediática e a lógica da acção judicial são conhecidas. Dessas disjunções decorrem perigos para a integridade do sistema judicial enquanto sistema autónomo de acção. As disjunções ocorrem a vários níveis. Ao nível dos tempos, entre os tempos 
instantâneos da comunicação social e os tempos processuais que, em confronto com os primeiros, surgem ainda mais lentos do que o que são. Ao nível das gramáticas discursivas codificadoras do relato dos factos e da distribuição das responsabilidades. A adjudicação judicial moderna tem como característica saliente criar dicotomias drásticas entre ganhadores e perdedores, mas só depois de aturados e prolongados procedimentos de contraditório e provas convincentes. A comunicação social partilha com os tribunais a primeira característica mas não a segunda. A primeira cria até uma cumplicidade entre tribunais e media que nem sempre é matizada pelas diferenças enormes que os dividem quanto à segunda característica. A cumplicidade ocorre ainda a outro nível: os processos judiciais tiveram sempre o potencial de se transformarem em dramas. Trata-se, porém, de um teatro para um auditório muito selecto, um teatro de culto profissional. Hoje, os meios de comunicação social, sobretudo a televisão, transformam esse teatro de culto num teatro de boulevard, espectáculo como entretenimento segundo uma linguagem directa e acessível a grandes massas.

Num contexto de crescente poder dos media, estas disjunções tendem a ser exploradas a seu favor. Acresce que, como os tribunais sempre se opuseram a ter por detrás de si o povo, ficam desarmados perante um adversário que traz consigo um povo muito curioso, talvez ressentido e, se não mesmo, sedento de vingança.

Aí residem os perigos da mediatização da justiça para a legitimidade social e política desta última. Cunha Rodrigues (1999, p. 51) identificou melhor que ninguém esses perigos:

a) o de, pelo "excesso de informação", se transmitir uma dimensão totalizante dos factos, susceptível de estigmatizar grupos ou classes sociais, gerando sentimentos de indignação, por um lado, e de indignidade, por outro;

b) a "sofisticação do escândalo", pela amplificação desproporcionada dos factos, provocando fracturas entre a opinião pública e a realidade; 
c) a sobrepenalização dos arguidos, pelas formas de mediatização utilizadas, sobretudo quando não se chama a atenção para a garantia constitucional de que os arguidos devem considerar-se inocentes até ao trânsito em julgado da decisão;

d) a espectacularização da audiência, produzindo na comunidade sentimentos contraditórios de absolutização ou de trivialização da justiça;

e) a banalização da violência ou dos modus operandi, com os conhecidos perigos de adesão ou mimetismo;

f) a conversão dos espectadores, ouvintes ou leitores em tribunal de opinião, com reflexos na produção da prova e nas expectativas de justiça;

g) o uso de linguagem nem sempre ajustada à racionalidade do discurso jurídico.

Destaco, ainda, o problema dos julgamentos paralelos realizados pelos meios de comunicação social, considerando que a investigação jornalística pode ajudar a investigação judicial, mas também pode provocar erros ou desvios, quer por intenção das fontes, quer pelo modo como a notícia se reflectiu negativamente na investigação e na fiabilidade das provas; os efeitos da mediatização nas testemunhas, podendo levar à produção de reflexos de auto-censura ou de vedetismo; e o perigo da feitura de justiça à medida da opinião pública, ao possibilitar que o elemento opinião pública, que os media ajudaram a formar, "entre" para a sala do tribunal podendo produzir reinterpretações do real no sentido da sua aproximação às expectativas da comunidade.

As dificuldades na relação entre a justiça e os media ficaram bem demonstradas no VI Congresso dos Juízes Portugueses que foi consagrado a esse tema. De modo lapidar, afirmou Orlando Afonso:

"A justiça é um serviço público sem dúvida, mas com uma função simbólica fundamental. Ora, o símbolo não age senão a uma distância respeitosa (...). Ora, os media fazem a abolição de três distâncias essenciais básicas na justiça: a delimitação de um espaço protegi- 
do, o tempo deferido do processo e a qualidade oficial dos actores do drama sócio-judiciário. A comunicação social desloca o espaço judiciário, paralisa o tempo e desqualifica a autoridade (...). A vigilância do jornalista é importante quando empenhada na denúncia de situações políticas, sociais e económicas graves, só que a comunicação social passa subrepticiamente da denúncia à desqualificação das instituições (...). A desqualificação da justiça operada pelos media exerce-se de duas formas aparentemente opostas: ou através da criação de uma desconfiança sistemática ou através da aproximação perigosa, quer uma, quer outra com o mesmo escopo: criar uma cultura de subordinação das instituições aos mais variados poderes sociais e económicos..." (Afonso, 2001).

Os tribunais sempre foram o órgão de soberania mais débil, por duas razões principais: porque sempre careceram de cooperação dos outros órgãos de soberania para fazer executar as suas sentenças e porque sempre dispensaram a obtenção de meios eficazes de comunicação com o público. É precisamente pela razão avançada por Orlando Afonso, pelo facto de terem optado pela comunicação simbólica que assenta na distância e na comunicação apenas por sinais e índices retóricos, isto é, por recurso a estratégias retóricas, que não fazem depender a anuência da inteligibilidade. Anuência mais por reverência do que por convencimento.

Daqui decorre a nova vulnerabilidade e a nova dependência dos tribunais ante a comunicação social. Por um lado, esta granjeia para os tribunais uma nova capacidade para executar autonomamente as suas sentenças. Trata-se de uma execução simbólica que permite criar a imagem do réu preso, de facto, um réu em liberdade preso a um discurso mediático de prisão merecida. Por outro lado, destroi a comunicação simbólica dos tribunais com o público, substituindo-a por uma comunicação pretensamente descritiva e próxima, desprovida de nuances, interessada 
no que se passou, por culpa de quem. Isto significa que, embora se recomende a melhoria da comunicação autónoma dos tribunais com o público, é bem possível que a socialização mediática dos cidadãos faça com que estes não consigam reconhecer essa comunicação e continuem a reclamar uma outra, a dos meios de comunicação social. Ou seja, o risco da mediatização da justiça é uma justiça incomunicável nos seus próprios termos.

Jacques Commaille e Antoine Garapon (1994, p. 9) promoveram junto dos estudantes do Sciences Po' de Paris a realização de dossiers de imprensa sobre o judiciário. Commaille (1994, p. 11-18) dá-nos a seguinte interpretação das conclusões dessa análise:

A relação de poder entre justiça e media é feito de interesses materiais e mercantis ideológicos, institucionais, profissionais, bem como de convicções e de valores. De facto, no jogo de espelhos entre a justiça e os media, a justiça não existe por si só, ela é "uma realidade socialmente construída". Este trabalho de construção social é, assim, favorecido pelas funções sociais atribuídas às duas partes: escrever ou mostrar as epopeias da sociedade no seu quotidiano pelos media; cumprir os rituais necessários, gerir o simbolismo indispensável para a coesão do grupo social e a sua perpetuação para a justiça.

A justiça e os media são, assim, constituídos em "espaço público", mas as respectivas funções sociais, que podem ser complementares, são susceptíveis de vir a ser concorrentes. A manifestação mais evidente da ruptura da complementaridade, no uso do espaço público, é a que podemos chamar de instrumentalização recíproca da justiça e dos media. Os media recorrem às fontes judiciárias por pretenderem assumir, aos olhos da sociedade, uma função de justiça que a justiça nunca conseguirá atingir de forma satisfatória. A justiça re- 
corre aos media à procura das estratégias que ajudem a situar o exercício da função de justiça no quadro das relações de força, exigindo tomar o social como testemunha, solicitar o seu concurso para fora dos limites temporais, institucionais, simbólicos, fixados pelo procedimento, pela instrução, pelo processo e pela sala de audiência.

E Commaille conclui:

O desafio que confrontará a justiça não será mais o de regredir ao período histórico em que a justiça participava num "jogo fechado entre indivíduos pertencentes a um número limitado de estatutos". A justiça terá de submeter-se a relações múltiplas com diferentes actores - entre os quais os media - funcionando cada vez mais "em capilaridade" dentro do tecido social, económico ou político. Terá de enfrentar uma regulação feita de micro-racionalidades justapostas, e de garantir a vigência das normas a que elas se referem e o respeito dos procedimentos, num contexto de desenvolvimento de um direito "intersticial e informal" e de uma normatividade "negociada", mais que "imposta".

Há que construir uma relação mais virtuosa entre a justiça e a comunicação social. É preciso desenvolver um programa de conhecimento recíproco, que permita impedir a perda de legitimidade, tanto dos tribunais como da comunicação social. A potencial conflitualidade e incomunicação entre os tribunais e a comunicação social tem raízes profundas. Assenta em práticas discursivas distintas e objectivos e culturas profissionais diferentes. É preciso partir do conhecimento destas diferenças para desenhar plataformas de cooperação entre tribunais e media. Numa sociedade info- 
democrática, a administração da justiça será tanto mais legitimada pelos cidadãos quanto mais conhecida e reconhecida for por eles. Os tribunais e a comunicação social são essenciais para o aprofundamento da democracia, pelo que é fundamental "estabelecer formas de coabitação no mesmo espaço social, estabelecer normatividade (normas jurídicas e de conduta) que regule e permita que a visibilidade da administração da justiça e do seu lugar, os tribunais" (Paquete de Oliveira, 1999, p. 27), seja ampliada e não distorcida pelos media. Para esse efeito deixo à vossa reflexão as seguintes propostas, de densidade e importância diferentes, com origem em "académicos ou em práticos", que devidamente ponderadas devem fazer o seu caminho caminhando.

1. Dar uma nova formação a juristas e a jornalistas - só assim se desenvolverá uma relação menos perversa e mais virtuosa, se compatibilizarão os discursos e se respeitarão os direitos, liberdades e garantias de todos os intervenientes. A interdisciplinariedade nesta formação poderá (des)construir a actual realidade e construir uma nova;

2. Reformar a actual Alta Autoridade para a Comunicação Social e institucionalizar um órgão com poderes disciplinares efectivos que coordene a gestão deontológica das empresas e profissionais da comunicação social - um órgão de composição heterogénea onde tenham assento representantes dos profissionais, dos agentes económicos da informação, do poder político e de organismos da sociedade civil;

3. Consagrar na lei a indemnização punitiva nos casos de violação de direitos de personalidade por órgãos da comunicação social (para além da indemnização por perdas e danos);

4. Desenvolver a auto-regulação por parte dos profissionais da comunicação social;

5. Criar uma providência cautelar, preventiva e específica, vocacionada para este tipo de violações (a "contempt court" inglesa);

6. Criar gabinetes de imprensa junto do Conselho Superior de Magistratu- 
ra ou de tribunais a definir;

7. Estabelecer a credenciação de jornalistas judiciários;

8. Adequar a publicidade de audiência e o segredo de justiça à nova sociedade de informação, o que implicará um reforço da estrutura acusatória e contraditório do processo criminal;

Com o desenvolvimento destas e outras propostas caminharemos para um maior equilíbrio entre o direito de informar e o respeito pelos direito de cidadania.

\section{Conclusões}

1. No que respeita ao impacto das novas tecnologias de comunicação e de informação na administração da justiça, abrem-se imensas oportunidades para melhorar a eficácia e racionalizar a gestão dos tribunais. Para isso, no entanto, três condições devem ser observadas. Em primeiro lugar, ao contrário do que pode parecer, o investimento tecnológico não dispensa o investimento no capital humano. Pelo contrário, exige a sua requalificação. A infomatização de muitas rotinas permite reduzir o número de funcionários, mas exige requalificar os que permanecem e, eventualmente, contratar outros para gerir as novas capacidades informacionais e comunicacionais.

A segunda condição é que haja sensibilidade e formação adequadas para enfrentar os novos conflitos inter-profissionais decorrentes das novas tecnologias e das mudanças de gestão que elas suscitam. Caminhamos para um tempo em que a aura simbólica dos magistrados não se sustenta sem capacidade gerencial efectiva.

A terceira condição é que os investimentos tecnológicos nos tribunais tenham um sentido político bem definido: melhorar o acesso dos cidadãos à justiça; corresponder ao incremento da competência informática dos cidadãos, abandonando de vez a ideia que o conhecimento técnico 
não é susceptível de ser comunicado aos cidadãos; apostar na eficácia não apenas para melhorar os índices quantitativos da actividade dos tribunais, mas sobretudo para aceder a uma nova qualidade da justiça.

Em suma, tal como está a suceder noutros sectores da sociedade, as novas tecnologias têm o potencial para devolver aos tribunais o papel de fonte de informação e de comunicação socialmente relevante.

2. Este novo papel é desempenhado num campo social conflitual onde se cruzam outros interesses informacionais e comunicacionais. As novas tecnologias informacionais e comunicacionais desenvolvem-se de par com novos interesses e novas lógicas informacionais e comunicacionais. São uns e outras que alimentam a dinâmica conflitual das relações entre tribunais e comunicação social. Quanto aos interesses, é importante conhecer o seu poder económico, o seu grau de concentração e o seu poder político. Ao contrário do que pretendeu até recentemente a vertigem neoliberal, não estamos em época de desregulamentação, mas sim em época de re-regulamentação. Está a abrir-se uma nova e imensa frente de relações entre o sector público e o sector privado. Duas condições distinguem esta frente da que caracterizou o período anterior. Por um lado, sendo em maior número os intervenientes e potencialmente maior o seu poder, a regulação é mais complexa e policêntrica e exige novas formas de controle público dos cidadãos. Por outro lado, a regulação terá de ser, em alguns dos seus aspectos mais decisivos, global e não nacional. Mas, para além dos interesses, há que contar com as diferentes lógicas informacionais e comunicacionais em conflito. Estas diferenças não têm sido adequadamente reconhecidas e, como tal, tanto os tribunais como os meios de comunicação social têm privilegiado um certo tacticismo de vistas curtas assente no princípio das instrumentalização recíproca, confiando cada um em que a sua capacidade de instrumentalizar o outro seja superior ao risco de ser instrumentalizado pelo outro. Há que pôr fim a este tacticismo, estabelecendo regras de relacionamento que respeitem as especificidades 
recíprocas à luz de uma ponderação ampla politicamente informada de bens jurídicos em conflito. Neste domínio, é crucial distinguir entre as situações em que o conflito é entre o acesso à informação, por um lado, e o segredo de justiça, o respeito da privacidade ou a obrigação de reserva, por outro, das situações em que o conflito é entre a informação juridicamente relevante e a construção mediática da notícia. É atendendo a este segundo conflito que se recomenda que os tribunais desenvolvam os seus próprios meios de comunicação com o público, remetendo-se a eles sempre que necessário. Há que encontrar novas vias que nos façam sair da opção entre tribunais reality shows e tribunais incomunicáveis.

3. Finalmente, a terceira conclusão é que as transformações informacionais e comunicacionais em curso, apesar de toda a retórica em contrário, não têm, até agora, contribuído para o aprofundamento da democracia. Como referi, esse aprofundamento passa pelo acesso à informação e pela criação de novas competências e possibilidades de intervenção dos cidadãos na vida pública. Ora, por um lado, a exacerbação dos direitos de propriedade intelectual é uma ameaça constante à ampliação do acesso e, por outro lado, as novas competências cidadãs têm estado a ser quase exclusivamente orientadas para o consumo e para a nova cultura de massas, a cultura de massas personalizada.

É urgente, pois, explorar as potencialidades democráticas das novas tecnologias, as novas possibilidades de democracia deliberativa e participativa, as novas formas de controle público, tanto do Estado como da produção privada de bens públicos. A relação virtuosa entre tribunais, comunicação social e novas tecnologias de informação e de comunicação depende menos daquilo que os três vectores deste triângulo acordarem entre si do que do controle público que sobre cada um deles exercerem os cidadãos activos, dotados de competências para exercícios de democracia de alta intensidade. 


\section{Referências}

AFONSO, Orlando. Poder judicial e opinião pública. Comunicação ao VI Congresso dos Juízes Portugueses. Justiça e opinião pública, tribunais e comunicação social: o olhar dos juízes portugueses. Disponível em: http://www.asjp.pt/ vicongresso/not0024.html. 2001

COMMAILLE, Jacques; GARAPON, Antoine. Dossier justice et médias. Revue Droit et Société, Paris, n.o 26, LGDJ, p. 3-94. 1994.

COMMAILLE, Jacques. L'exercice de la fonction de justice comme enjeu de pouvoir entre justice et médias. Revue Droit et Société, Paris, n.o 26. LGDJ,p. 11-18. 1994.

PAQUETE DE OLIVEIRA, José Manuel. A comunicação social e os tribunais. Subjudice. 15/16. DocJuris: Viseu. 1999. p. 23-28.

RODATÀ, Stefano. Para uma cidadania electrónica: A democracia e as novas tecnologias de comunicação. In CARDOSO, Gustavo; CARAÇA, João; MONTEPEGADO, Tiago (coord.). Presidência da República - Debates. Os cidadãos e a sociedade de informação. Imprensa Nacional Casa da Moeda. 2000.

RODRIGUES, Cunha. Comunicar e julgar. Coimbra: Edições Minerva. 1999.

SANTOS, Boaventura de Sousa; MARQUES, Maria Manuel Leitão; PEDROSO, João; FERREIRA, Pedro. Os tribunais nas sociedades contemporâneas. $\mathrm{O}$ caso português. Porto: Ed. Centro de Estudos Sociais, Centro de Estudos Judiciários e Edições Afrontamento. 1996.

SANTOS e GOMES (coord.). A administração e gestão da justiça- análise comparada das tendências de reforma. Coimbra: Observatório Permanente da Justiça Portuguesa/Centro de Estudos Sociais. 2001.

SCHUMPETER, Joseph. Capitalism, Socialism and Democracy. 3rd. edition. New York: Harper and Row. (1962 [1942]). 


\section{Resumo}

Este artigo discute como, a partir da década de 1990, a problemática da relação entre os tribunais e as novas tecnologias de comunicação e de informação (NTCl) e, em especial, da relação entre os tribunais e a comunicação social, coloca novas questões para uma análise das relações entre as instituições de justiça e a sociedade. De um lado, surge a questão da vontade e da capacidade do Estado e do Direito para regular as novas tecnologias e os novos interesses de comunicação e de informação, bem como para incriminar e punir as novas atividades socialmente danosas que, por via delas, tornaram-se possíveis. De outro lado, o impacto da expansão exponencial das novas tecnologias e dos novos interesses informacionais e comunicacionais no Direito e nas suas instituições, nomeadamente os tribunais. São debatidas questões como a informatização dos tribunais, as novas técnicas de gestão e seus impactos nas relações inter-profissionais, na mediatização da justiça, na funcionalidade interna dos tribunais e nas regras e estilos de atuação profissional, assim como, o impacto das novas tecnologias de comunicação e de informação e, sobretudo, dos meios de comunicação na relação entre os tribunais e a sociedade informatizada e mediatizada. Conclui afirmando a necessidade de explorar as potencialidades democráticas das novas tecnologias, as novas possibilidades de democracia deliberativa e participativa, as novas formas de controle público, tanto do Estado como da produção privada de bens públicos.

Palavras chave: Tribunais, novas tecnologias de informação e comunicação, capacidade regulatória do direito 


\section{Courts and the new communication and information technologies}

Boaventura de Sousa Santos

This article discusses how, after the 1990s, the problem of the relationship between Law courts and new communication and information technologies (NCIT) and especially that between courts and social communication, poses new issues to an analysis of relations between judiciary institutions and society. On the one hand, there emerges the State's capacity and will to regulate new technologies and new communication and information interests, as well as to incriminate and punish new socially harmful activities that became possible through those technologies; on the other hand, there is impact of the enormous expansion of new technologies and new informational and communicational interests within Law and its institutions, namely Law Courts. The article debates issues such as computerization of courts, new management techniques and their impacts on interprofessional relations, on a media-based justice, on the internal functionality of Courts, on rules and styles of professional action, as well as the impact of new information and communication technologies - and above all, of the media - on the relation between courts and a computerized and media-oriented society. It concludes by sustaining the need to explore the democratic potential of new technologies, the new possibilities of deliberative and participatory democracy, new forms of public control both over the State and over private production of public goods.

Key Words: Courts, New communication and information technologies, State regulatory capacity 